\title{
Psychometric Properties of Cognitive Behavioral Scientific Insight Questionnaire
}

\author{
Hengameh Aminaei Chatroudi, ${ }^{1}$ Afsaneh Towhidi $\mathbb{D}^{2},{ }^{2}$ and Mohsen Madadi $\mathbb{D}^{3}$ \\ ${ }^{1}$ Department of Education, Faculty of Literature and Humanities, Shahid Bahonar University of Kerman, Kerman, Iran \\ ${ }^{2}$ Department of Psychology, Faculty of Literature and Humanities, Shahid Bahonar University of Kerman, Kerman, Iran \\ ${ }^{3}$ Department of Statistics, Faculty of Mathematics and Computer, Shahid Bahonar University of Kerman, Kerman, Iran
}

Correspondence should be addressed to Afsaneh Towhidi; atowhidi@uk.ac.ir

Received 1 October 2021; Revised 24 October 2021; Accepted 5 January 2022; Published 22 February 2022

Academic Editor: Syed Sameer Aga

Copyright (@) 2022 Hengameh Aminaei Chatroudi et al. This is an open access article distributed under the Creative Commons Attribution License, which permits unrestricted use, distribution, and reproduction in any medium, provided the original work is properly cited.

\begin{abstract}
Scientific insight is a cognitive and behavioral task. Although as a concept or a measure that sounds very familiar, so far not even one tool was found to measure the cognitive behavioral scientific insight (CBSI). Due to the lack of a questionnaire in this field, the researchers aimed to design a cognitive behavioral scientific insight questionnaire (CBSIQ) and to determine its validity. Therefore, the researchers designed the CBSIQ with 105 questions on a five-point Likert scale, and then 205 university faculty members were asked to complete the tool. The faculty members were recruited using stratified sampling and within each stratum using simple random sampling methods. The data were analyzed using exploratory factor analysis (EFA) and confirmatory factorial analysis (CFA). Results show that CBSIQ ended with 33 questions constituting three factors: scientific thinking and applying scientific methods, scientific moral and commitment, and speaking in scientific terms. It is concluded that the CBSIQ is valid with relatively good fit indices. The implication of the CBSIQ is that it provides the key factors to diagnose individuals' thinking obstacles; it can act as a framework to design instructional packages in order to teach people how to think insightfully and how to solve their problems scientifically or, in other words, how to acquire a scientific insight. Therefore, CBSIQ has the capability to function as a useful tool and as a remedy specifically to diagnose and resolve educational problems.
\end{abstract}

\section{Introduction}

The concept of "science" in its broad notion is generally defined as a systematic search for acquiring knowledge [1], searching for causes and laws [2,3], affirming certain things that humans believe in [4], searching and constructing knowledge [5], and explaining disconnected phenomena [6]. Although science might be considered as an institution for allocating talent and brain drain [7], its real main purpose is supposed to be rejecting dogma, mandating authority, processing thinking, finding the truth, and reflecting social interactions [8]. The concept and the goal of science are that citizens respect it [9], appreciate scientific insight [10], believe that science in nature is a cross-cultural phenomenon being capable of solving difficulties [11], and commensurate that science is the contribution of all scientists around the world as science belongs to the whole world, to all races, to all cultures, and, in other words, to all humanity $[12,13]$. Defining scientific insight is a hard task. Although scientific insight appears to be a common and familiar term, it is not elaborated well, and it is not understood very well either.

A close term to scientific insight is scientific thinking. But what is scientific thinking? Scientific thinking deals with applying the methods or principles of scientific inquiries in order to understand, reason, and solve problems in different situations [14], employing necessary skills in order to generate, test, and derive theories and their revision, acquiring skills to comprehend and gain the procedures, and 
reflecting the knowledge acquisition $[15,16]$. In these definitions, the emphases are on methods of inquiries, problem solving, and acquiring theories and knowledge.

The second question (what is the scientific method?) is arising now. The scientific method is defined as an inductive approach and logical and orderly way of thinking in building theories or laws through testable hypotheses involving data gathering [17]. It seems that these two definitions are very similar to the definition of scientific thinking as their emphases are on testing hypotheses, data gathering, problem solving, building theories, and knowledge. As Dewey [18] confirms, in a sense, science is both the subject and the method, but Al-Ahmadi [19] discusses that although sometimes the "scientific thinking" and "scientific method" are used synonymously, they are vague terms.

The third question is "what is scientific insight?" To answer this question, in the searched literature, there are many articles that define and introduce "scientific thinking" and "scientific method" along with introducing their components, but when it comes to the issue of scientific insight, the literature is very limited.

Langley and Jones [20] do not define what scientific insight is, but they consider scientific discoveries as instances of scientific insight. For example, the discoveries of the principle of displacement by Archimedes, the ring structure of the benzene molecule by Louis Kekule, Fuchsian functions by Henri Poincare, and many other similar events are the representation of scientific insights.

On the issue of "scientific insight as a belief," we found not even one research. The closest one is Clement [21] who discusses that scientific thinking and scientific method could be the closest cognitive concepts that may contribute to explaining the "scientific insight." Rudolph advocates that science is an insight that makes changes in people's thoughts and lifestyles [22]. In psychology, science is an exploration of brain's complex metacognitive tasks such as reflecting and directing behaviors [23] and the ability to solve problems [14]. Rudolph [22], Carter-Thomas and Rowley-Jolivet [24], and Dunbar [25] confirm this matter in a different sense and advocate that science is an insight as well. Thus, we can say that science has the capability to be the cause of people's change of beliefs, thinking, and lifestyles. It is realized that scientific thinking and scientific method are focusing on methodology. Although scientific insight may seem similar to the mentioned terms, in the present research, the emphasis is put on having the insight as a belief, as a reflection, as a cognitive behavioral phenomenon, and as the application of individuals' values in their everyday life.

As the definition of science changes, naturally, the insight or attitude toward science changes as well; thereby, this is what the present research is trying to explore. Many disciplines, including psychology and educational psychology, mostly emphasize "scientific thinking" and "scientific method" as close concepts to scientific insight. These concepts were searched, and the following discussions emerged.

Due to the evolution of knowledge, science is categorized into different (yet, similar) eras of positivism, postpositivism, constructivism-interpretivism, and criticalideological research paradigms [26]. Howe [27] classifies it into three positivist dogmas: qualitative-quantitative (incompatible with the separation of qualitative and quantitative researches), fact-value (separation of facts and values), and empirical science-humanities (based on the association with cultures and practices, separating science-oriented and humanities-oriented researches). Aliyu et al. [28] classify the paradigms into two main methods of positivism (quantitative) and postpositivism (qualitative). Both positivism and postpositivism sustain different versions of reality and views on knowledge-knowing, which gather empirical data or evidence. Positivism is the main important feature. Both the qualitative and quantitative methods share the gathering of empirical data or evidence. However, classifying science under positivism and postpositivism paradigms is more popular than other classifications.

Historically, in the early 19th century, positivism was developed by Auguste Comte as an epistemology and as a theory of progress in society [29], claiming that knowledge (science) is a kind of behavior that should be derived from direct observation through senses and it should be objective, perceptible, noticeable, discernible, and measurable [30]. Science in this view is defined as a cognitive meaningful concept that is tested and verified through experiences and well-defined experimentations. In the positivistic and experimental perspectives-as endorsed, for instance, in the Austrian-British philosopher Karl Raimund Popper's view-if a theory can be falsified, then that theory is considered scientific. So, ethics and aesthetics have no place as scientific issues [31]. Postpositivism has a different view on science. It has its roots in the views of Willard van Orman Quine and Thomas Samuel Kuhn, challenging the logical perspectives of positivism (logic and mathematics) [29] and the epistemology of science as the accumulation of knowledge. In the postpositivistic view, science is bound to relativism, and nothing is absolute. Rörsch [32] explains that the concept of positivism has changed into relativism since the nineteenth century. This means that respect for seeing things from different points of view has emerged among scientists. Kuhn [33] believes that knowledge is constructed in people's communities and within their social interactions. As Wong [34] discusses, postpositivism is largely based on the social invention of knowledge, meaning that knowledge is the product of social consensus and social experiences that shape one's perception of reality and truth. At the macrolevel, knowledge or truth is constructed and shaped by cultural forces and institutionalized practices. At the microlevel, on a day-to-day basis in individuals' discourses and social interactions, the construction of the truth is constantly produced and redefined. Dewey [18, 35] and Benedek et al. [36] put the emphasis on transparency, truthfulness, dignity, and respecting diverging opinions that are the intrinsic values of all democratic societies.

Since science by itself is an entity, it has to be classified under a category. Thus, simply, we can classify science under positivism and postpositivism. The other common classification of scientific findings is to classify it under theories. Here, for this matter, many theories are elaborated and discussed. 
Gestalt theory of insight learning does not talk about scientific insight, but the theory defines insight as a problemsolving process in which learning is an insight by which the organism learns to restructure his mental representations through mental cognitive trial and error and understanding the relationships among problem difficulties and mental impasses [20, 37-39]. Lee [40] and King et al. [41] claim that, in this view, Gestalt ethics and values have prominent places in the problem-solving process. Skottun and Krüger [42] note that Wertheimer and Lewin's ideas were applied in psychotherapy later.

Ohlsson's restructuring theory is derived from the integration of Gestalt theory and the problem space framework. A Gestalten is formed as a result of many pre-wellformed structures in the mind. When structures are changed into unbalanced structures and gaps (e.g., unsolved problems), restructuring occurs, meaning that the problem is carefully analyzed and resolved. During the restructuring process, a different way of seeing the problem is evolved, meaning that people are able to anticipate the goal. When any impasse happens, the person looks at the situation from a different angle, a new restructuring occurs, the problem is resolved, and a flash of insight appears. Passing through these phases becomes possible through the description space for a problem. This means that, in the restructuring process, a different way of seeing the problem from a different perspective is provided $[20,43]$. We can infer that, in the Gestalt theory, forming a Gestalten is a cognitive activity that resolves the problem.

Hadamard's theory of scientific insight explains that an insight occurs in distinct phases of preparation (an intense effort to solve the problem), incubation (abandonment of the problem for a while and conscious processing), illumination (solution appears unexpectedly and suddenly), and verification (verifying the solution) [20]. Simon's theory of familiarization and selective forgetting integrates human memory with information processing models of problem solving. Based on the information processing models, a human has a limited capacity of short-term memory, and he/ she is able to restore up to seven items, one at a time. For this, he/she forms chunks of familiar items such as letters, words, sentences, and/or even phrases (called the familiarization process). This occurs consciously through heuristic search within the problem space, then higher levels of structures are constructed, and eventually, the chunks are restored in the long-term memory. If the problem happens to be beyond the ability of the human, the problem is put aside, and structures in the short-term memory would wane (called selective forgetting). When later the person decides to solve the problem, since the chunks still exist in the long-term memory, they would help the person move toward the goal faster than before. Then by combining the process of familiarization with the selective forgetting process, the problem is solved in a different mode [20]. We see that these theories explain how an insight occurs.

Analogy is an important phase in forming a scientific theory. For instance, Archimedes' analogy of his body with king's crown is a scientific analogy. In this respect, Dreistadt's analogy-based theory of insight is based on the human making analogies of his own similar to the problem that he is supposed to solve. Another theory is Hall's framework for analogy, in which reasoning by analogy has to map existing structures. First, the person starts with an incomplete description of the vague and an incomplete target; then, he/she retrieves the needed stuff from long-term memory (called the recognition process); after that, he/she analyses and evaluates the reasonability of the analogy. If the mapping is acceptable, then he/she fills up the target description (called the elaboration stage). For future use, he would restore the successful and abstract version of the analogy (called the consolidation process). In Gentner's structure mapping theory, strong analogies from the poor ones are made. The theory provides evaluation criteria for carrying out the elaboration processes in three steps (disregarding the objects' attributes, preserving the relationship between objects, deciding on what attributes should be reserved and selected). Winston's theory of analogy focuses on different aspects of the analogical reasoning processes on a hierarchical order, meaning that each subtype reminds the earlier one in a hierarchical manner. In Carbonell's theory of derivational analogy, the emphasis is on how a problem is indexed, retrieved, and consolidated. In confronting with a new problem, the choice is applying the weak problem-solving methods (e.g., heuristic search or means-ends analysis), then the usage of the acquired previous knowledge of the solutions is integrated into solving the current problem, and if it is not resolved, then different routes are found [20]. The main concept of the analogical theories was to derive an analogy and, based on that analogy, solve the novel problem.

Besides theories of scientific insight, there are general theories that are classified under the current theories of insight. For instance, in the representational change theory, when a person confronts a problem since the goal is already known, the person compares it with similar problems of the past experience, and the problem is solved. In the process, an unconscious process steps in, and by generating alternative strategies, an insight happens. If impasses happen, then conscious concentration happens, which leads to new ideas until the person solves the problem. The dynamic constraint theory (DCT) postulates that, in the problem-solving processes, when the person puts aside the misleading heuristics, at that moment, an insight happens. The main assumption of this theory is that the person may use inadequate and misleading heuristics, meaning that an impasse is occurring. When the person finds an appropriate heuristic, it means that the insight is happening [43]. The constraint theory deals with ethics and values in its own way directly and proposes what ought to be done or not to be done directly [44]. The criterion for satisfactory progress theory is a model with two main components of searching for mechanism in order to find the possible moves in the problem and expanding the mechanism in order to discover novel moves that are not available at the time of solving the problem [45]. The fixation theory deals with putting aside the unwarranted constraints, and as a result, a solution space is provided. Associationistic theory talks about searching explicit and implicit memories in parallel that may lead to many associations. Evolutionary theory builds nonexisted associations. 
Through evaluations, implicit associations are assessed and selected by the explicit processes [38]. Michael Polanyi's theory of tacit knowledge explains that "we know more than we can tell." Although this theory is specifically on leaching learning processes, it bears a philosophical approach through using the central feature of intellectual passions, values, and ethics [46-48]. This model is integrated from three models of the Gestalten concept of the part-whole, the incorporative phenomenological existential or intentional aspects of knowing of the action-guiding model, and the inferences of the semiotic model. An "inference" happens through understanding the reality and introducing the truth. In this model, the integration process is not necessarily a conscious phenomenon. The semiotic model is Polanyi's main concept in developing hierarchical, logical, and ontological concepts [48]. Whatever theories define the scientific insight, it is essentially a cognitive task that manifests in a behavior called an insightful behavior $[38,39,49,50]$. In these theories, we see that the main idea is explaining how the process of insight happens.

There is this claim that, without considering the complexity and sophistication of theories of insight, we have to have an operational definition of an insightful event, and we have to define what constitutes the insightful event. Depending on the situation, if the insightful event does not verify the theory, in order to advocate the falsifiability, the theory has to be revised and remodified [39]. Weisberg emphasized that the definition of an insight should be explained within the context of a theory [39]. Upon our investigations, we found that some measures in scientific thinking and scientific method are introduced $[16,19]$, but there is not even one tool measuring the cognitive behavioral scientific insight (CBSI) concept. Based on this notion, the components of CBSI are elaborated as follows.

Problem solving is an essential part of the scientific insight [21]. As individuals endeavor to solve problems, they may arrive at clear and sudden solutions through insight which is usually called the "Aha!" experience [51]. To solve a problem, there is a need for intuition, inspiration, and enthusiasm [52]. Allan and Chisholm [53] list many ethical qualifications called global (universal) ethical qualifications, including coping and communicating with the communities that are racially, culturally, ethnically, and linguistically diverse. They are respecting others, valorizing the determinants views, thinking and analyzing in a reflective manner to solve problems, continuously reviewing and improving cultural competence at all levels of personal and professional work, and advocating social justice.

Scientists make many decisions through evidencebased materials, cause-effect principles [54], and higher levels of thinking strategies called time management skills [55]. A critical issue in scientific insight is self-creativity being related to intelligence [36]. Intelligence (intelligent behavior) is defined as an insight or behavior being conducted in accordance with the structure of a given visual field [56]. Creativity contains novelties and values [57]. Having curiosity, using rational methods, solving problems, creative novelty, being objective and having no biases, and choosing the truth are the characteristics of individuals with scientific insight [58]. Objectivity, imagination, and learned adaptability are the scientific insight components as well [59]. Scientific insight is respecting others, respecting learning about knowledge, and applying that knowledge, in other words, learning how to think scientifically [16]. This insight encompasses all the good qualities such as tolerance, being humble, fairness, passion, and assertiveness $[16,60]$. Comte, in his positivist view, suggests the theory of progress concerning the overall advancement (progression) of the human race [29]. Caputo [11] mentions that humans need scientific knowledge in order to have empathy in today's world in dealing with difficulties. They need nonpersonalized science synthesizing apathy and warmness to make the world a better place to live in for all its human inhabitants.

Obstacles happen in the lives of individuals at any personal, cultural, social, economic, and/or political level due to inadequate scientific thinking and not believing in a CBSI. In today's world, in order to solve many global obstacles, there is a need to find ways to construct CBSIs and measure them. Based on the literature, we noticed that the main theme of the mentioned theories is explaining how an insight and a scientific insight happen. They explain the insightful phases and the mental processes that take place during the insightful experience, but they do not explain the scientific insight construct and its components. We also realize that there is no specified model pertaining to the cognitive behavioral characteristics of the scientific insight; thus, we tried to have an operational definition and a measure for the scientific insight; therefore, due to the limited literature on this subject in educational psychology in both conventional and Internet-based searching systems, as a necessity, we designed a tool called cognitive behavioral scientific insight questionnaire (CBSIQ). Thus, the aims of the present research are to answer the following research questions:

(1) What is the definition of CBSI? Or in other words, what are the comprising main factors and components of the CBSIQ?

(2) Do the components of CBSIQ are confirmed in the second analysis?

(3) Does the CBSIQ preserve the necessary validation, and would it integrate its indices?

Our research is theoretically based on Gestalt because our scientific insight is a cognitive act. We also advocate Polanyi's theory of tacit knowing because we put the emphasis on the teaching-learning process, morals, and explicit domains of human knowledge. CBSIQ would be able to diagnose people's misleading behaviors; thus, our research is based on the dynamic constraint theory as well.

\section{Materials and Methods}

The present research uses a descriptive method of factorial analysis kind. The statistical population consisted of all university faculty members of the main campus $(N=468)$. To determine the sample size Farshchi's [61] online sample 
size calculation with Cochran's formula [ $(N$ : statistical population; $\mathrm{z}$ : equal to $1.96 ; p=q=0.50$; $d$ : permissible error value (error value))] was used. The software estimated the sample size to be 211 . Thus, 211 faculty members were recruited based on the stratified sampling method and within each stratum using the simple random sampling method. Eventually, only 205 members participated in completing the questionnaires. In factor analysis, according to Comrey and Lee [62], 205 seems to be a fair size.

The age of faculty members ranged from 25 to 66 years $(M=41.99, \mathrm{SD}=9.19) ; 61(29.80 \%)$ of all faculties were females, and $144(70.20 \%)$ of them were males with their teaching experiences ranging from one year to 35.00 years $(M=12.65 ; \mathrm{SD}=9.30)$. The number and the percentages of the faculties were 68 literature and humanities (71\%), 9 veterinary medicine (4.4\%), 19 mathematics and computer (9.3\%), 32 science (15.6\%), 1 physical education (.5\%), 27 engineering (13.2\%), 9 economics (4.4\%), 9 architecture (4.4\%), 23 agriculture (11.2\%), and 5 being unknown (2.4\%).

In order to gather the needed data, a researchers' made tool called CBSIQ was designed:

(1) According to the literature, 105 items of a CBSIQ using a one-to-five-point Likert scale were developed. Then, CBSIQ was handed over to 10 faculty members (with their consent) to determine the facial validity. Reviewing the opinions led to discarding some of the items.

(2) Then, the content validity was administrated using the panel of experts (30 faculty members), and some repetitive and vague concept items were discarded.

(3) The necessary guidelines were provided in CBSIQ, and the demographic information and completion of the main items were requested. 205 faculty members (with their consent) completed the CBSIQ.

(4) CBSIQs were gathered right after the completion, and the CBSIQ was analyzed. Those items that raised the reliability of the tool were discarded.

(5) Although Chan and Luk [63] and Doron et al. [64] allow a factor to be formed by two items, in order to improve the CBSIQ further, two-item factors were discarded and eventually, 33 items constituted the CBSIQ.

(6) Using the exploratory factorial analysis (EFA), the factors were extracted, and by referring to specialists and educators, the factors were named.

(7) At the end, a confirmatory factorial analysis (EFC) was conducted to confirm the CBSIQ extracted factors.

2.1. Statistical Analyses. For descriptive statistics (such as mean and standard deviation) and inferential statistics (such as EFA), the IBM-Statistical Package for the Social Sciences (IBM-SPSS) version 20 was used, and for CFA, the linear structural relations 8 (LISREL-8) was used.

\section{Results}

Descriptive results of CBMSI distribution are presented in Table 1. To explore the normality of data Kolmogorov-Smirnov test (K-S test), Skewness and Kurtosis were conducted, and the results are also shown in Table 1.

Based on Table 1, scientific thinking and applying scientific methods has the highest mean of 83.81 with a standard deviation of $14.69(M=83.81 ; \mathrm{SD}=14.69)$. This table also shows that none of the distributions were normal, so the compute dialog of the SPSS scores of the factors was applied to normalize the data.

Test of homogeneity of variances is presented in Table 2.

Eigenvalue is the measure for the explained variance accounted by each factor (component), meaning that the largest eigenvalue is the most important one [65]. Based on Costa and Sarmento [66] and Wipulanusat et al. [67] criteria, only those factors that pertained to eigenvalues higher than one were kept for interpretations.

The results of the EFA, using Oblimin rotation, are presented in Table 3.

Meyers et al. [68] consider 0.70 of KMO or above as adequate and good values of showing multicollinearity and highly significant chi-squared $\left(\chi^{2}\right)$ outcomes. Costa and Sarmento [66] consider the KMO of 0.90 to 1.00 to be better measures.

Table 4 shows the sampling adequacy of KMO and Bartlett's measures.

Based on Table 4, the KMO indicates a high value. Bartlett's test of sphericity shows that the factorial analysis is reliable and the factors are related to one another significantly $\left(\chi^{2}=4768.67, \mathrm{df}=528\right.$, and $\left.\operatorname{sig}=0.0001\right)$. Thus, it was concluded that the conditions for executing factorial analyses were reliable.

The scree test would identify the correct number of factors and its suitability for having a sense of the number of factors [69]. The communalities represent the relationship between each item and all other items [65]. Figure 1 shows the scree plot showing the directions of the three adequate factors.

Figure 1 is the scree plot that shows the 33 items of the directions of the adequate three factors.

Results of the Oblimin factorial rotation are presented in Table 5. $p \leq 0.0001$.

Table 6 shows that the assumption of reasonable linearity between factors and the assumption of not having any multicollinearity is met.

The composite reliability measures all factors' internal reliabilities (or internal consistency) [67]. For this, the acquired Cronbach's alpha value should be greater than 0.70 ([63], Cronbach [70]). For factor reliabilities, their $R^{2}$ values should be greater than 0.50; their factor weights should be significant; the AVE should exceed 0.50 and greater than the error variances (meaning that the convergent validity is fairly good) [67]. Raykov and Marcoulides [71] specifically note that " $t$ value is greater than +2 or less than -2 , the parameter is referred to as significant at the used significance level (typically 0.05)" (p. 33). 
TABLE 1: Descriptive results of the CBSIQ distribution and factors' test of normality.

\begin{tabular}{|c|c|c|c|c|c|c|c|c|}
\hline Factor & Min. & Max. & $M$ & SD & Skewness & Kurtosis & Statistic & Sig. \\
\hline Scientific thinking and applying scientific methods & 39.00 & 110.00 & 83.81 & 14.69 & -0.51 & 0.28 & 0.07 & 0.01 \\
\hline Scientific moral and commitment & 13.00 & 35.00 & 25.54 & 4.84 & 0.004 & -0.64 & 0.08 & 0.001 \\
\hline Speaking in scientific terms & 3.00 & 10.00 & 7.58 & 1.44 & -0.42 & -0.41 & 0.15 & 0.0001 \\
\hline
\end{tabular}

TABLE 2: Results of CBSIQ factors testing the homogeneity of variances.

\begin{tabular}{|c|c|c|c|c|}
\hline Factor & Levene statistic & df1 & $\mathrm{df} 2$ & Sig. \\
\hline Scientific thinking and applying scientific methods & 0.10 & 1 & 200 & 0.75 \\
\hline Scientific moral and commitment & 0.07 & 1 & 201 & 0.78 \\
\hline Speaking in scientific terms & 0.008 & 1 & 203 & 0.92 \\
\hline
\end{tabular}

Data in Table 2 show that the factors are homogeneous.

TABLE 3: Eigenvalue, explained, and accumulated percentage of explained variances.

\begin{tabular}{lccc}
\hline Factors & Eigenvalue & \% of explained variance & Accumulated percentage of explained variance \\
\hline Scientific thinking and applying scientific methods & 16.99 & 51.49 & 51.49 \\
Scientific moral and commitment & 1.69 & 5.15 & 56.64 \\
Speaking in scientific terms & 1.30 & 3.94 & 60.58
\end{tabular}

Table 3 shows that the extraction of three main factors accounts for $60.58 \%$ of the common variance.

TABLE 4: KMO and Bartlett's test using EFA.

\begin{tabular}{lcc}
\hline \multicolumn{2}{c}{ Kaiser-Meyer-Olkin measure of sampling adequacy } & \\
& Approx. $\chi^{2}$ & 0.96 \\
Bartlett's test of sphericity & $\mathrm{df}$ & 4768.67 \\
& Sig. & 528 \\
\end{tabular}

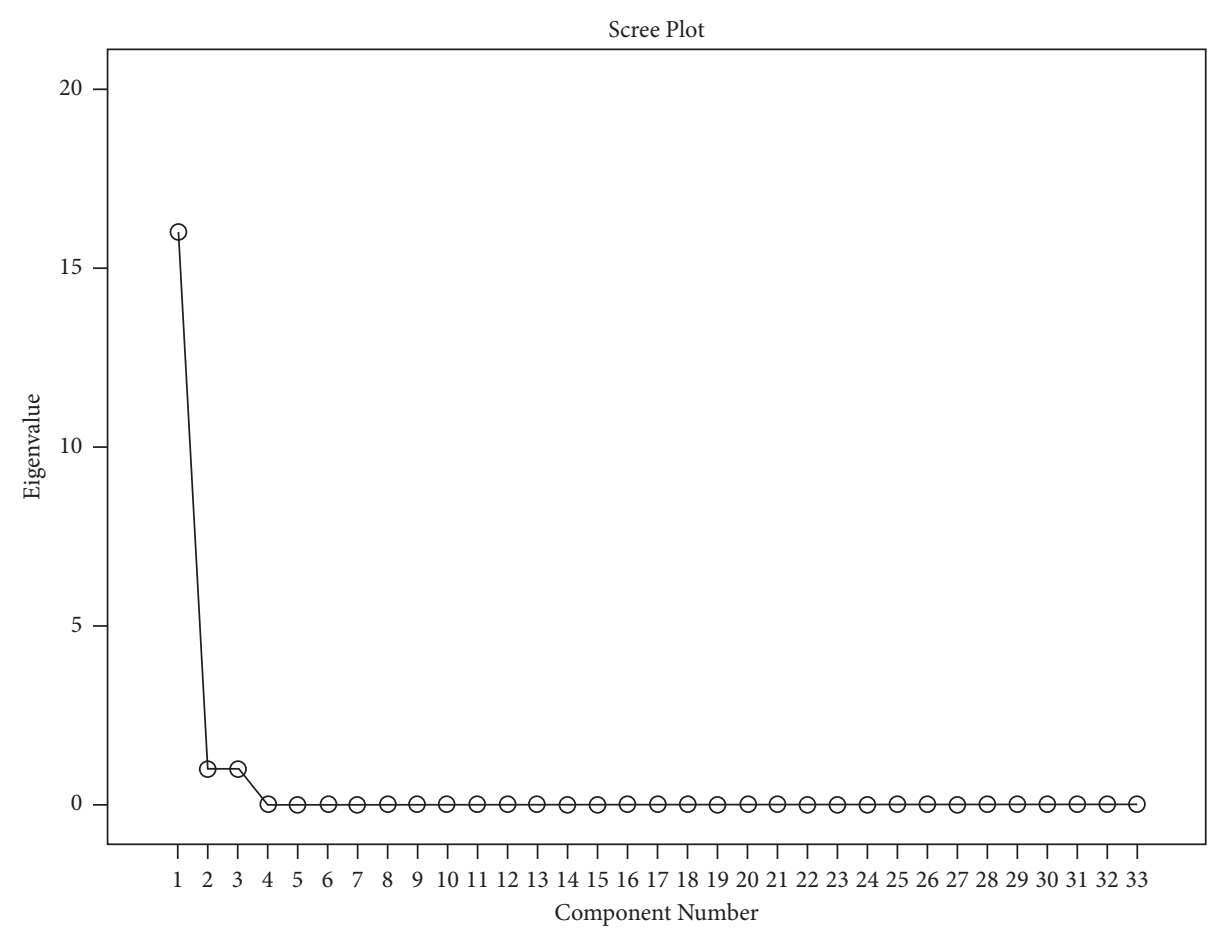

Figure 1: The scree plot and the directions of the factors. 
TABLE 5: Results of EFA.

\begin{tabular}{|c|c|c|c|c|c|c|}
\hline Factors (scales) & & Items & Communalities & 1 & 2 & 3 \\
\hline \multirow{20}{*}{$\begin{array}{l}\text { Scientific thinking and applying } \\
\text { scientific methods }\end{array}$} & 1 & $\begin{array}{c}\text { In supporting discussions and investigations, they use the } \\
\text { latest scientific sources }\end{array}$ & 0.59 & 0.67 & & \\
\hline & 2 & $\begin{array}{c}\text { In discussions and solving problems, they apply scientific } \\
\text { methods }\end{array}$ & 0.53 & 0.60 & & \\
\hline & 3 & They are precise and accurate & 0.56 & 0.68 & & \\
\hline & 4 & They think about their environment with careful thought & 0.50 & 0.46 & & \\
\hline & 5 & They value time and save time & 0.60 & 0.78 & & \\
\hline & 6 & They encourage individuals in conducting research & 0.55 & 0.68 & & \\
\hline & 7 & $\begin{array}{c}\text { They use computers and other advanced instruments when } \\
\text { doing research }\end{array}$ & 0.46 & 0.77 & & \\
\hline & 8 & $\begin{array}{c}\text { They have the optimum ability in using time and its } \\
\text { management }\end{array}$ & 0.76 & 0.96 & & \\
\hline & 9 & Having skills in self-creativity & 0.53 & 0.73 & & \\
\hline & 10 & $\begin{array}{c}\text { They have intuition, inspiration, and creative minds (being } \\
\text { novel and nurturing new ideas) }\end{array}$ & 0.55 & 0.66 & & \\
\hline & 11 & They think comprehensively and have broad perspectives & 0.62 & 0.73 & & \\
\hline & 12 & $\begin{array}{c}\text { They always update their knowledge with the latest } \\
\text { advancements }\end{array}$ & 0.66 & 0.83 & & \\
\hline & 13 & They advocate the justice & 0.62 & 0.48 & & \\
\hline & 14 & They are rational and do not make decisions impulsively & 0.59 & 0.55 & & \\
\hline & 15 & They are objective (lack of subjective judgment) & 0.68 & 0.63 & & \\
\hline & 16 & They look for causes & 0.71 & 0.70 & & \\
\hline & 17 & They act assertively instead of merely talk & 0.64 & 0.68 & & \\
\hline & 18 & $\begin{array}{c}\text { They provide an environment for experimentation and } \\
\text { thinking }\end{array}$ & 0.71 & 0.74 & & \\
\hline & 19 & $\begin{array}{c}\text { They are eager to solve the scientific, social, and emotional } \\
\text { problems of individuals }\end{array}$ & 0.52 & 0.58 & & \\
\hline & 20 & They enjoy reading & 0.64 & 0.73 & & \\
\hline \multirow{9}{*}{ Scientific moral and commitment } & 21 & They avoid being superficial & 0.58 & & 00.53 & \\
\hline & 22 & $\begin{array}{l}\text { If they do not know something, they confess to their lack of } \\
\text { knowledge }\end{array}$ & 0.56 & & 00.61 & \\
\hline & 23 & $\begin{array}{c}\text { In their everyday life, they consider other people's } \\
\text { perspectives }\end{array}$ & 0.58 & & 00.75 & \\
\hline & 24 & $\begin{array}{c}\text { In their life affairs, they set thinking about the relationships } \\
\text { among phenomena }\end{array}$ & 0.56 & & 00.50 & \\
\hline & 25 & They have the essential flexibilities & 0.75 & & 00.91 & \\
\hline & 26 & They avoid fury & 0.60 & & 00.63 & \\
\hline & 27 & They are without bias & 0.68 & & 00.60 & \\
\hline & 28 & They have morality and commitment & 0.53 & & 00.52 & \\
\hline & 29 & They are enthusiastic & 0.50 & & 00.34 & \\
\hline \multirow{5}{*}{ Speaking in scientific terms } & 30 & They behave and solve problems with compromises & 0.55 & & & 55 \\
\hline & 31 & They are assertive in talking & 0.61 & & & 0.56 \\
\hline & 32 & They do not interrupt other individuals' talks & 0.64 & & & 0.52 \\
\hline & 33 & $\begin{array}{c}\text { They do not have any sexual, cultural, racial, and/or ethnical } \\
\text { prejudices }\end{array}$ & 0.51 & & & 0.58 \\
\hline & & Average communality & 0.57 & & & \\
\hline
\end{tabular}

Table 5 shows that there are three extracted factors.

TABLE 6: Matrix of factorial correlations.

\begin{tabular}{lcccc}
\hline & Factor & 1 & 2 & 3 \\
\hline 1 & Scientific thinking and applying scientific & & & \\
methods & 1 & & \\
2 & Scientific moral and commitment & 0.78 & 1 & \\
3 & Speaking in scientific terms & 0.73 & 0.57 & 1 \\
\hline
\end{tabular}

Results of CFA, the latent factor relationships and their indicator (item) evaluations are shown in Table 7.
Based on Table 7, the $t$ value for all items is above 2 $(t>2)$, meaning that all relationships are significant and the model pertains to a good fit. Results of CFA confirmed the same three factors. Since the value of Cronbach's alpha exceeds 0.70, the CBSIQ has satisfactory internal reliability.

The heterotrait-monotrait ratio of correlations (HTMT) is a new way of estimating discriminant (divergent) validity than the traditional ones. In HTMT, the discriminant validity of each factor is compared with the validity of another one through two-by-two cross-loadings [72]. According to 
TABLE 7: Results of CFA and evaluation of indicators.

\begin{tabular}{|c|c|c|c|c|c|c|c|c|}
\hline Factor & $\begin{array}{l}\text { Indicator } \\
\text { (item) }\end{array}$ & $\begin{array}{c}\text { Standardized } \\
\text { quotient }\end{array}$ & $\begin{array}{c}t \\
\text { value }\end{array}$ & $R^{2}$ & $\begin{array}{c}\text { Composite } \\
\text { validity }\end{array}$ & AVE & Reliability & $\begin{array}{l}\text { Global } \\
\text { reliability }\end{array}$ \\
\hline \multirow{20}{*}{$\begin{array}{l}\text { Scientific thinking and applying } \\
\text { scientific methods }\end{array}$} & 1 & 0.80 & 11.25 & 0.65 & \multirow[t]{20}{*}{0.98} & \multirow[t]{20}{*}{0.62} & \multirow[t]{20}{*}{0.96} & \multirow[t]{20}{*}{0.97} \\
\hline & 2 & 0.75 & 11.01 & 0.57 & & & & \\
\hline & 3 & 0.74 & 10.94 & 0.52 & & & & \\
\hline & 4 & 0.78 & 11.63 & 0.59 & & & & \\
\hline & 5 & 0.71 & 10.31 & 0.54 & & & & \\
\hline & 6 & 0.61 & 11.98 & 0.79 & & & & \\
\hline & 7 & 0.59 & 8.12 & 0.34 & & & & \\
\hline & 8 & 0.80 & 12.30 & 0.68 & & & & \\
\hline & 9 & 0.70 & 10.21 & 0.53 & & & & \\
\hline & 10 & 0.77 & 11.62 & 0.60 & & & & \\
\hline & 11 & 0.83 & 12.95 & 0.71 & & & & \\
\hline & 12 & 0.82 & 12.61 & 0.67 & & & & \\
\hline & 13 & 0.77 & 11.51 & 0.58 & & & & \\
\hline & 14 & 0.78 & 11.77 & 0.60 & & & & \\
\hline & 15 & 0.86 & 13.58 & 0.73 & & & & \\
\hline & 16 & 0.88 & 14.15 & 0.77 & & & & \\
\hline & 17 & 0.86 & 13.64 & 0.76 & & & & \\
\hline & 18 & 0.86 & 13.64 & 0.76 & & & & \\
\hline & 19 & 0.72 & 10.44 & 0.50 & & & & \\
\hline & 20 & 0.87 & 13.92 & 0.72 & & & & \\
\hline \multirow{9}{*}{ Scientific moral and commitment } & 21 & 0.69 & 9.90 & 0.42 & \multirow[t]{9}{*}{0.98} & \multirow[t]{9}{*}{0.53} & \multirow[t]{9}{*}{0.89} & \\
\hline & 22 & 0.74 & 10.66 & 0.53 & & & & \\
\hline & 23 & 0.71 & 10.01 & 0.54 & & & & \\
\hline & 24 & 0.76 & 11.59 & 0.56 & & & & \\
\hline & 25 & 0.81 & 12.26 & 0.68 & & & & \\
\hline & 26 & 0.64 & 9.04 & 0.40 & & & & \\
\hline & 27 & 0.83 & 12.80 & 0.73 & & & & \\
\hline & 28 & 0.72 & 10.83 & 0.43 & & & & \\
\hline & 29 & 0.68 & 9.44 & 0.42 & & & & \\
\hline \multirow{4}{*}{ Speaking in scientific terms } & 30 & 0.72 & 10.38 & 0.52 & \multirow[t]{4}{*}{0.96} & \multirow[t]{4}{*}{0.52} & \multirow[t]{4}{*}{0.78} & \\
\hline & 31 & 0.76 & 11.26 & 0.57 & & & & \\
\hline & 32 & 0.76 & 11.41 & 0.63 & & & & \\
\hline & 33 & 0.64 & 8.78 & 0.39 & & & & \\
\hline
\end{tabular}

Gold et al. [73] and Teo et al. [74], for a construct with a reasonable validity, HTMT should be lower than 0.90 .

In Table 8, the two-by-two factor comparisons using HTMT are shown.

In Table 8, since all of the HTMT estimates are lower than 0.90 , it is concluded that there is a discriminant validity among the three factors. In accordance with the significance of factor weights (greater than 0.70 ), the convergent validity is confirmed, too.

In CFA, for confirming the convergent validity, there are some indices $[65,67,75,76]$.

To ensure the fit model, the fit indices were estimated, and the results are presented in Table 9.

Table 9 shows that the model has relatively good fit indices $\left(\chi^{2}=1227.54 ; \mathrm{df}=429, \quad p=0.0001, \quad \chi^{2} / \mathrm{df}=2.86\right.$, $\mathrm{RMSEA}=0.089, \quad \mathrm{GFI}=0.90, \quad \mathrm{AGFI}=0.89, \quad \mathrm{NFI}=0.95$, $\mathrm{IFI}=0.97$, and $\mathrm{CFI}=0.097$ ).

\section{Discussion}

To answer the first question of the research, based on all the aforementioned characteristics, CBSI is defined as a belief and as a commitment to science, to self, and to the global
TABLE 8: HTMT for comparing two-by-two factors.

\begin{tabular}{ccccc}
\hline & Factor & 1 & 2 & 3 \\
\hline 1 & Scientific thinking and applying scientific & & & \\
methods & $*$ & & \\
2 & Scientific moral and commitment & 0.86 & $*$ & \\
3 & Speaking in scientific terms & 0.85 & 0.77 & $*$ \\
\hline
\end{tabular}

humanities in sustaining the ethics, truth, values, and scientific methods in all its aspects in order to treat self and others in the most respectful and the humane ways with no sexual, cultural, racial, and/or ethnical prejudices. CBSIQ is constituted of three factors of scientific thinking and applying scientific methods, scientific moral and commitment, and speaking in scientific terms. In the second analysis, the CBSIQ is confirmed to have three factors. Even one measure has not been found to investigate the CBSIQ. Ethics, values, and truth are the key and core solutions that are the core issues in Gestalt [40, 41]. In Polanyi's theory, since tacit knowledge is highly personal and context-specific and has its roots in the personal experiences of the people, it deals with ethics, truth, and values [42]. The constraint theory takes ethical issues into consideration and determines what ought 
TABLE 9: Indices of model fit indices and the estimated CFI indices.

\begin{tabular}{lcccccccccc}
\hline Indices & $\chi^{2}$ & $\mathrm{df}$ & $\chi^{2} / \mathrm{df}$ & $p$ & GFI & AGFI & NFI & CFI & IFI & RMSEA \\
\hline Cut-off criteria & - & - & $1-5$ & $>0.05$ & 0.90 & $>0.90$ & $\geq 0.95$ & $>0.90$ & $>0.90$ & $0.06-0.08$ \\
CFI gained indices & 1227.54 & 429 & 2.86 & 0.0001 & 0.90 & 0.89 & 0.95 & 0.09 & 0.97 & 0.08 \\
\hline
\end{tabular}

to and what ought not to be done [44]. Thus, CBSIQ is in concordance with Polanyi's beliefs and emotions and the constraint theory in dealing with science.

To answer the second question of the research, the CBSIQ is confirmed to have three factors. To justify the CBSIQ development, there are some obstacles in many societies. Anastopoulou et al. [60] recall them as shortmindedness, prejudice, dogmatism, lack of looking at the issues from different perspectives in terms of information and sources, impulsive judgments in confronting with other individuals' perspectives and opinions, and diminishing the questioning spirit, specifically among youngsters about science, society, and the world's problems. Surely, in these kinds of circumstances, in confronting with problems, the process of progression and development of the society will suffer; individuals will show less strength; and their reactions will not be based on analysis, wisdom, cognition, and awareness. King et al. [40] and Skottun and Krüger [42] mention that the Gestalt therapy is an extensive method for resolving people's emotional problems, helping people to solve their daily life obstacles and their emotional problems.

Scientific thinking cannot be acquired unless learners become mature and earn enough experience in sciences [19]. When individuals learn something, it is expected that this awareness will cause a change in their behaviors. Thus, it is expected that scientists and scientific earnings would make many changes in individuals' thoughts and lifestyles. In other words, people expect many things from knowledgeable individuals that they may not normally expect from common people [25]. Polanyi believes that his tacit theory of knowledge offers an objective truth and a belief in universality [46].

In general, due to the observations, it has become obvious that morality is very significant in man's scientific insight. Without a doubt, no one is content with what he/she has, and no one stops at or bounds himself/herself to any limitations. But all believe in values. Values such as dignity and truth [34]. Polanyi in his theory of knowledge deeply believes in the universality of knowledge, morality, and respect for the truth [46].

To answer the third question of the research, it can be said that the CBSIQ is a valid model. For these purposes, at first, after investigating many related sources, items of scientific insight were identified. Then by using the proper statistical techniques, the main items of the scientific insight were determined, and based on the results of the EFA, CBSIQ was categorized into 33 items with three main extracted factors. Overall, CBSIQ is valid, and it contains relatively good fit indices.

\section{Conclusion}

The purpose of the present study was to define CBSI, design CBSIQ, and diagnose its factors and its validation. Although even one measure has not been found to investigate the scientific insight, we reached a definition and a measurement of a more elaborated concept of the scientific insight called cognitive behavioral scientific insight (CBSI), and we also designed a tool to measure CBSI named cognitive behavioral scientific insight questionnaire (CBSIQ). The CBSIQ is a valid model. Overall, it is concluded that the integrated model is valid with relatively good fit indices. We have concluded that scientific insight is scientific thinking and thinking style. It is an attitude affecting individuals' way of life, beliefs, and acts. Having a scientific way of thinking would help people to be different from other members of their societies. This insight would help people to be kept away from any kind of prejudices in terms of gender, culture, race, and/or ethnics. The scientific insight would help people to be rational, assertive, considerate, and open to gaining new experience and help them live in justice. Eventually, the CBSIQ is a valid and reliable instrument to measure all the mentioned qualities.

5.1. Implications and Suggestions. Findings on CBSIQ in the present research are novel. The concepts are subjective, but the methodology is objective. Thus, both the positivism and postpositivism views are integrated, and CBSIQ findings have contributed to enhancing literature on scientific insight. It also has practical implications for schools and higher institutions. In order to reinforce the scientific insight, the CBSIQ provides key factors acting as a framework in exploring the concept empirically. The researchers, educational psychologists, and/or all educational practitioners can use the CBSIQ in conducting researches and detecting individuals' views in order to ameliorate peoples' life challenges. The CBSI can be a good remedy in resolving cultural and social problems. CBSI can work as a framework to design instructional packages in teaching people how to think and solve their problems with insightful and scientific approaches. Therefore, CBSIQ has the capability to function as a useful tool in helping learners, educators, and therapists.

5.2. Limitations. The sample was limited to university faculty members of a specific culture. We did not control the gender, age, and years of faculty teaching experiences. It is suggested to conduct similar researches on different samples with different races and cultures in different settings. It is recommended to design a CBSIQ instructional package and examine its effectiveness in resolving cultural and social problems.

\section{Data Availability}

The data used to support the findings of this study are included within the supplementary information files. 


\section{Conflicts of Interest}

The authors declare no conflicts of interest.

\section{Acknowledgments}

The authors appreciate university faculty members for their collaboration in completing the CBSIQ.

\section{Supplementary Materials}

The data of the paper are given. (Supplementary Materials)

\section{References}

[1] K. Bschir, S. Lohse, and H. Chang, "Introduction: systematicity, the nature of science?" Synthese, vol. 196, no. 3, pp. 761-773, 2019.

[2] D. Ary, L. C. Jacobs, C. K. S. Irvine, and D. Walker, Introduction to Research in Education, Cengage Learning, Boston, MA, USA, 2018.

[3] M. Granatella, "Imaginative universals and human cognition in the new science of Giambattista Vico," Culture \& Psychology, vol. 21, no. 2, pp. 185-206, 2015.

[4] E. Aflalo, "Advancing the perceptions of the nature of science (NOS): integrating teaching the NOS in a science content course," Research in Science \& Technological Education, vol. 32, no. 3, pp. 298-317, 2014.

[5] C. Perjan and S. Sanduleac, "Increasing the quality of university studies through the development of students' scientific thinking," Applied Researches in Technics, Technologies and Education, vol. 16, no. 2, pp. 195-201, 2018.

[6] Y. J. Kim and C.-B. Zhong, "Ideas rise from chaos: information structure and creativity," Organizational Behavior and Human Decision Processes, vol. 138, pp. 15-27, 2017.

[7] A. Vega-Muñoz, P. Gónzalez-Gómez-del-Miño, and J. F. Espinosa-Cristia, "Recognizing new trends in brain drain studies in the framework of global sustainability," Sustainability, vol. 13, no. 6, p. 3195, 2021.

[8] E. F. Keller, "Climate science, truth, and democracy," Studies in History and Philosophy of Science Part C: Studies in History and Philosophy of Biological and Biomedical Sciences, vol. 64, pp. 106-122, 2017.

[9] K. Vohland, A. Land-Zandstra, L. Ceccaroni et al., The Science of Citizen Science, Springer, Berlin, Germany, 2021.

[10] E. R. Kandel, The Age of Insight: The Quest to Understand the Unconscious in Art, Mind, and Brain, from Vienna 1900 to the Present, Random House Incorporated, New York, NY, USA, 2012.

[11] A. Caputo, "A brief scale on attitude toward learning of scientific subjects (ATLoSS) for middle school students," Journal of Educational, Cultural and Psychological Studies (ECPS Journal), vol. 16, no. 16, pp. 57-76, 2017.

[12] S. Reiss, K. Garrigan, B. Mixon, D. Hunter, B. Quade, and D. Zaninno, Transforming the World through Science, National Science Foundation, Alexandria, VA, USA, 2017.

[13] L. Soete, S. Schneegans, D. Eröcal, B. Angathevar, and R. Rasiah, UNESCO Science Report: Towards 2030-Executive Summary, https://uis.unesco.org/sites/default/files/documents/ unesco-science-report-towards-2030-part1.pdf, UNESCO, Paris, France, 2015, https://uis.unesco.org/sites/default/files/ documents/unesco-science-report-towards-2030-part1.pdf.

[14] S. Prayogi and N. N. S. P. Verawati, "The effect of conflict cognitive strategy in inquiry-based learning on preservice teachers' critical thinking ability," Journal of Educational, Cultural and Psychological Studies (ECPS Journal), vol. 21, pp. 27-41, 2020.

[15] S. Venkataraman, "A review on scientific attitude among higher secondary students," Journal of Xi'an University of Architecture and Technology, vol. 13, no. 1, pp. 372-391, 2021.

[16] C. Zimmerman, "The development of scientific thinking skills in elementary and middle school," Developmental Review, vol. 27, no. 2, pp. 172-223, 2007.

[17] J. van der Graaf, E. van de Sande, M. Gijsel, and E. Segers, “A combined approach to strengthen children's scientific thinking: direct instruction on scientific reasoning and training of teacher's verbal support," International Journal of Science Education, vol. 41, no. 9, pp. 1119-1138, 2019.

[18] J. Dewey, "Science as subject-matter and as method," Science, vol. 31, no. 787, pp. 121-127, 1910.

[19] F. Al-Ahmadi, "The development of scientific thinking with senior school physics students," Dissertation, University of Glasgow, Scotland, UK, 2008, https://theses.gla.ac.uk/241/.

[20] P. Langley and R. Jones, "A computational model of scientific insight," in The Nature of Creativity: Contemporary Psychological Perspectives, R. J. Sternberg, Ed., pp. 177-201, Cambridge University Press, Cambridge, UK, 1988.

[21] J. Clement, Creative Model Construction in Scientists and Students: The Role of Imagery, Analogy, and Mental Simulation, Springer, Dordrecht, Netherlands, 2008.

[22] J. L. Rudolph, "Turning science to account Chicago and the general science movement in secondary education, 1905-1920," Isis, vol. 96, no. 3, pp. 353-389, 2005.

[23] M. V. J. Veenman, "Metacognition: "Know thyself". Use that knowledge especially to regulate your own behavior," $D e$ Psycholoog, vol. 50, pp. 8-18, 2015, Proceedings of the 15th European Congress of Psychology, Psychology addressing Society's greatest Challenges, Amsterdam, Netherlands.

[24] S. Carter-Thomas and E. Rowley-Jolivet, "Open science notebooks: new insights, new affordances," Journal of Pragmatics, vol. 116, pp. 64-76, 2017.

[25] K. Dunbar, "How scientists think in the real world: implications for science education," Journal of Applied Developmental Psychology, vol. 21, no. 1, pp. 49-58, 2000.

[26] M. Yvonne Feilzer, "Doing mixed methods research pragmatically: implications for the rediscovery of pragmatism as a research paradigm," Journal of Mixed Methods Research, vol. 4, no. 1, pp. 6-16, 2010.

[27] R. B. Johnson, "Comments on Howe: toward a more inclusive "scientific research in education"," Educational Researcher, vol. 38, no. 6, pp. 449-457, 2009.

[28] A. A. Aliyu, M. U. Bello, R. Kasim, and D. Martin, "Positivist and non-positivist paradigm in social science research: conflicting paradigms or perfect partners?" Journal of Management and Sustainability, vol. 4, no. 3, pp. 79-95, 2014.

[29] J. H. Zammito, A Nice Derangement of Episteme; Post-positivism in the Study of Science from Quine to Latour, The University of Chicago Press, Chicago, IL, USA, 2004.

[30] F. Crossan, "Research philosophy: towards an understanding," Nurse Researcher, vol. 11, no. 1, pp. 46-55, 2003.

[31] J. Waugh and R. Ariew, "The history of philosophy and the philosophy of science from," in The Routledge Companion to Philosophy of Science, C. Martin and S. Psillos, Eds., pp. 27-37, Routledge, London, UK, 2013.

[32] A. Rörsch, "The progress of science-past, present and future," Humanities, vol. 3, no. 4, pp. 442-516, 2014.

[33] É. Rubat du Mérac, "The revised educational context perception questionnaire (ECPQ II): psychometric proprieties," 
ECPS-Educational, Cultural and Psychological Studies, vol. 1, no. 15, pp. 53-72, 2017.

[34] Y. J. Wong, "Strength-centered therapy: a social constructionist, virtues-based psychotherapy," Psychotherapy: Theory, Research, Practice, Training, vol. 43, no. 2, pp. 133-146, 2006.

[35] J. Dewey, Reconstruction in Philosophy, Henry Holt and Company, New York, NY, USA, 1920.

[36] M. Benedek, E. Jauk, M. Sommer, M. Arendasy, and A. C. Neubauer, "Intelligence, creativity, and cognitive control: the common and differential involvement of executive functions in intelligence and creativity," Intelligence, vol. 46, pp. 73-83, 2014.

[37] I. K. Ash, B. D. Jee, and J. Wiley, "Investigating insight as sudden learning," The Journal of Problem Solving, vol. 4, no. 2, p. 2, 2012.

[38] S. Hélie and R. Sun, "Incubation, insight, and creative problem solving: a unified theory and a connectionist model," Psychological Review, vol. 117, no. 3, pp. 994-1024, 2010.

[39] J. W. Schooler, M. Fallshore, and S. M. Fiore, "Epilogue: putting insight into perspective," in The Nature of Insight, R. J. Sternberg and J. E. Davidson, Eds., pp. 559-587, MIT Press, Cambridge, MA, USA, 1996.

[40] R. G. Lee, "Ethics: a gestalt of values/the values of Gestalt: a next step," Gestalt Review, vol. 6, no. 1, pp. 27-51, 2002.

[41] D. B. King, M. Wertheimer, H. Keller, and K. Crochetière, "The legacy of Max Wertheimer and gestalt psychology," Social Research, vol. 61, no. 4, pp. 1934-1994, 1994.

[42] G. Skottun and Å. Krüger, Gestalt Therapy Practice: Theory and Experiential Learning, Routledge, London, UK, 2021.

[43] G. Knoblich, M. Öllinger, and M. J. Spivey, "Tracking the eyes to obtain insight into insight problem solving," in Cognitive Processes in Eye Guidance, G. Underwood, Ed., Oxford University Press, Oxford, UK, 2005.

[44] J. Broome, "Introduction I: the structure of good," in Weighing Goods: Equality, Uncertainty and Time, pp. 1-21, John Wiley \& Sons, Hoboken, NJ, USA, 2017.

[45] J. N. MacGregor, T. C. Ormerod, and E. P. Chronicle, "Information processing and insight: a process model of performance on the nine-dot and related problems," Journal of Experimental Psychology: Learning, Memory, and Cognition, vol. 27, no. 1, pp. 176-201, 2001.

[46] S. Gourlay, "Tacit knowledge, tacit knowing, or behaving?," 2002, https://warwick.ac.uk/fac/soc/wbs/conf/olkc/archive/ oklc3/papers/id269.pdf.

[47] J. M. Jamison, "Authentic space," https://pdffox.com/ jamison2018redactedpdf-pdf-free.html Professional thesis, The University of Edinburgh, Edinburgh, UK, 2018,

[48] S. R. Jha, "A new interpretation of Michael Polanyi's theory of tacit knowing: integrative philosophy with "intellectual passions", Studies in History and Philosophy of Science Part A, vol. 28, no. 4, pp. 611-631, 1997.

[49] T. Khalili, "Recognition is an effective step to make a scientific insight in students," Journal of Basic and Applied Scientific Research, vol. 2, no. 4, pp. 4542-4549, 2012.

[50] E. Segal, "Incubation in insight problem solving," Creativity Research Journal, vol. 16, no. 1, pp. 141-148, 2004.

[51] E. Bowden, M. Jungbeeman, J. Fleck, and J. Kounios, "New approaches to demystifying insight," Trends in Cognitive Sciences, vol. 9, no. 7, pp. 322-328, 2005.

[52] X. Gu, Y. Shao, X. Guo, and C. P. Lim, "Designing a role structure to engage students in computer-supported collaborative learning," The Internet and Higher Education, vol. 24, pp. 13-20, 2015.

[53] M. Allan and C. U. Chisholm, "The formation of the engineer for the 21st century-a global perspective," in Proceedings of the 20th Australasian Association for Engineering Education Conference, University of Adelaide, Adelaide, Australia, December 2009.

[54] D. M. Rousseau, "Is there such a thing as "evidence-based management"?" Academy of Management Review, vol. 31, no. 2, pp. 256-269, 2006.

[55] H. Hartman, Human Learning and Instruction, City College of City University of New York, New York, NY, USA, 2002.

[56] R. van der Veer, "The concept of development and the development of concepts. Education and development in Vygotsky's thinking," European Journal of Psychology of Education, vol. 9, no. 4, pp. 293-300, 1994.

[57] M. L. Gruys, N. V. Munshi, and T. C. Dewett, "When antecedents diverge: exploring novelty and value as dimensions of creativity," Thinking Skills and Creativity, vol. 6, no. 2, pp. 132-137, 2011.

[58] N. Reid, "Attitude development through a science curriculum," Dissertation, University of Glasgow, Scotland, UK, 1978, https://search.proquest.com/ openview/cfd09f40a74e52c00a9f93a1082b95d8/1?pqorigsite $=$ gscholar $\& \mathrm{cbl}=2026366 \&$ diss $=\mathrm{y}$.

[59] R. D. Jarrard, Scientific Methods. An Online Book, University of Utah, Salt Lake City, UT, USA, 2001, https://www.iibhg. ukim.edu.mk/Obrazovanie/sm_all.pdf.

[60] S. Anastopoulou, M. Sharples, S. Ainsworth, C. Crook, C. O’Malley, and M. Wright, "Creating personal meaning through technology-supported science inquiry learning across formal and informal settings," International Journal of Science Education, vol. 34, no. 2, pp. 251-273, 2012.

[61] S. M. Farshchi, "Online sample size calculation with Cochran's formula + instructional video," 2020, https://www. spss-iran.com/sample-size/.

[62] R. C. MacCallum, K. F. Widaman, S. Zhang, and S. Hong, "Sample size in factor analysis," Psychological Methods, vol. 4, no. 1, pp. 84-99, 1999.

[63] C. K. Y. Chan and L. Y. Y. Luk, "Development and validation of an instrument measuring undergraduate students' perceived holistic competencies," Assessment \& Evaluation in Higher Education, vol. 46, no. 3, pp. 467-482, 2020.

[64] J. Doron, R. Trouillet, K. Gana, J. Boiché, D. Neveu, and G. Ninot, "Examination of the hierarchical structure of the brief COPE in a French sample: empirical and theoretical convergences," Journal of Personality Assessment, vol. 96, no. 5, pp. 567-575, 2014.

[65] N. L. Leech, K. C. Barrett, and G. A. Morgan, SPSS for Intermediate Statistics: Use and Interpretation, Psychology Press, Hove, UK, 2005.

[66] V. Costa and R. P. Sarmento, "Confirmatory factor analysis, a case study," 2019, https://arxiv.org/ftp/arxiv/papers/1905/ 1905.05598.pdf.

[67] W. Wipulanusat, K. Panuwatwanich, and R. A. Stewart, "Workplace innovation: exploratory and confirmatory factor analysis for construct validation," Management and Production Engineering Review, vol. 8, no. 2, pp. 57-68, 2017.

[68] L. S. Meyers, G. C. Gamst, and A. J. Guarino, Performing Data Analysis Using IBM SPSS, John Wiley \& Sons, Hoboken, NJ, USA, 2013.

[69] R. B. Cattell, "The scree test for the number of factors," Multivariate Behavioral Research, vol. 1, no. 2, pp. 245-276, 1966.

[70] A. McCormac, D. Calic, K. Parsons, T. Zwaans, M. Butavicius, and M. Pattinson, "Test-retest reliability and internal consistency of the human aspects of information security questionnaire (HAIS-Q)," in Proceedings of the Australasian Conference on 
Information Systems ACIS 2016, vol. 56, Wollongong, Australia, December 2016.

[71] T. Raykov and G. A. Marcoulides, A First Course in Structural Equation Modeling, Routledge, London, UK, 2012.

[72] J. Henseler, C. M. Ringle, and M. Sarstedt, "A new criterion for assessing discriminant validity in variance-based structural equation modeling," Journal of the Academy of Marketing Science, vol. 43, no. 1, pp. 115-135, 2015.

[73] A. H. Gold, A. Malhotra, and A. H. Segars, "Knowledge management: an organizational capabilities perspective," Journal of Management Information Systems, vol. 18, no. 1, pp. 185-214, 2001.

[74] T. S. H. Teo, S. C. Srivastava, and L. Jiang, "Trust and electronic government success: an empirical study," Journal of Management Information Systems, vol. 25, no. 3, pp. 99-132, 2008.

[75] J. B. Schreiber, A. Nora, F. K. Stage, E. A. Barlow, and J. King, "Reporting structural equation modeling and confirmatory factor analysis results: a review," The Journal of Educational Research, vol. 99, no. 6, pp. 323-338, 2006.

[76] J. Sun, "Assessing goodness of fit in confirmatory factor analysis," Measurement and Evaluation in Counseling and Development, vol. 37, no. 4, pp. 240-256, 2005. 